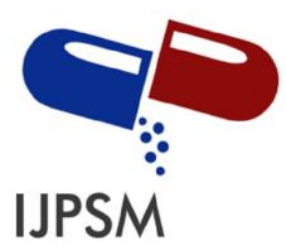

Seema U. Shinde et al, Int. Journal of Pharmaceutical Sciences and Medicine (IJPSM),

Vol.6 Issue. 5, May- 2021, pg. 45-52

ISSN: 2519-9889

Impact Factor: 3.426

\title{
Development and Evaluation of Antibacterial Polyherbal Bath Soap
}

\author{
Seema U. Shinde ${ }^{1}$; Nikita D. Gidde ${ }^{2}$, Jamir. A. Tamboli ${ }^{3}$ \\ Rajarambapu College of Pharmacy, Kasegaon (MS) India 415404 \\ Email id - seemashinde5197@gmail.com \\ DOI: 10.47760/ijpsm.2021.v06i05.006
}

\begin{abstract}
Address for Correspondence:
Nikita Gidde D.

Rajarambapu College of Pharmacy, Kasegaon (MS)

Email id- nikitagidde19@gmail.com
\end{abstract}

Contact Number: 9561042889

\begin{abstract}
Bacterial skin infections are the most prevalent among individuals, necessitating immediate treatment as well as ongoing care to preserve healthy skin. Because some herbal plant extracts have antibacterial properties, the goal of this research is to make an antibacterial poly herbal bath soap using curcuma longa[Turmeric] and Organum Vulgare [Oregano The antibacterial activity of prepared soap was evaluated against staphylococcus aureus, E. coli, and Aspergillus Niger using the agar well diffusion technique. The developed Polyherbal formulation had a good antibacterial activity, and it was analysed for several physicochemical parameters and whether it has good characteristics. Plants are easily obtainable, and their efficacy helps manufacturers in achieving cost-effective outcomes with few or no side effects.
\end{abstract}

Keywords: Antibacterial, Herbal, Zone of inhibition, Extract, Soap 


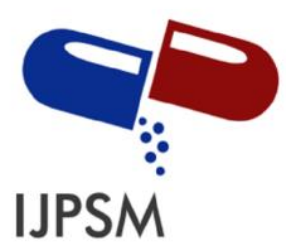

Seema U. Shinde et al, Int. Journal of Pharmaceutical Sciences and Medicine (IJPSM), Vol.6 Issue. 5, May- 2021, pg. 45-52

ISSN: 2519-9889

Impact Factor: 3.426

\section{Introduction:}

The skin, also known as the cutaneous membrane, protects the body's external surface. In terms of surface area and weight, it is the body's largest organ. Body temperature control, blood storage, protection from the external environment, cutaneous sensations, excretion and absorption, and vitamin D production are all functions of the skin. The skin is the most exposed area of the body to the sun, pollutants, and viruses while yet providing some protection. Eczema, warts, acne, rashes, psoriasis, allergies, and other skin conditions are the most frequent. ${ }^{1,2}$

Skin disorders are one of the most serious public health issues because they affect both people and communities. Pain, suffering, impairment of normal functioning, and a lower quality of life are all consequences. As a result of the increased use of dangerous synthetic chemicals in skin care products, the prevalence of certain skin illnesses is on the rise. ${ }^{3}$

Hand hygiene is important in preventing contagious diseases by protecting the skin from infectious microorganisms and their spread. ${ }^{4}$ Many chemical antiseptics are now accessible as alcohol-based sanitizers, Chlorohexidine preparations, and other forms. This poly herbal soap or solution helps to prevent healthcareassociated infectious disease transmission more efficiently, although it has certain drawbacks or side effects. ${ }^{5}$

Plants that have therapeutic characteristics have been employed as traditional medicine since the dawn of mankind. Medicinal plant extracts from the leaves, stems, and roots have been used as a natural cure for a variety of maladies and disorders. Despite the fact that many plant-based medicines have been supplanted by synthetic chemicals, ayurvedic goods' safety and usefulness have not been proven. ${ }^{6}$

In comparison to chemical goods, herbal treatments have the benefit of being inexpensive, readily available, and having less adverse effects. ${ }^{7}$ As a result, research has accelerated in the direction of developing natural goods that are higher in quality, less costly, and have no adverse side effects when compared to chemical products. ${ }^{8}$

The purpose of this study was to develop Poly-herbal bath soap using extracts of curcuma longa[Turmeric], Organum Vulgare [Oregano], and investigate the antibacterial/antimicrobial activity of the extract against important causative bacteria. Additionally, to assess the physicochemical properties of the prepared formulations in order to standardize and commercialize them. 


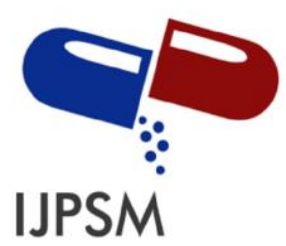

Seema U. Shinde et al, Int. Journal of Pharmaceutical Sciences and Medicine (IJPSM), Vol.6 Issue. 5, May- 2021, pg. 45-52

ISSN: 2519-9889

Impact Factor: 3.426

\section{Material and Methods:}

\section{Material:}

Curcuma longa [Turmeric] and Organum Vulgare [Oregano] were collected from various areas and localities in Maharashtra, India. RCP in Kasegaon, Maharashtra, provided sodium hydroxide, palm oil, coconut oil, castor oil, glycerine, ethyl alcohol, sugar, ethanol, steric acid cinnamon oil, and orange oil. Chemicals of analytical grade are employed in the preparation

\section{Methods:}

\section{Preparation of Extracts:}

Curcuma longa

In the Soxhlet apparatus, the Curcuma longa powder was subjected to a 6-hour hot continuous extraction process with $70 \%$ alcohol and 30\% water. The solvent was evaporated and concentrated to dry residue after full extraction. ${ }^{9}$

\section{Organum Vulgare}

The organum vulgare powder was extracted with ethanol in a Soxhlet apparatus for three hours, after which the solvent was evaporated and the dry residue concentrated. ${ }^{10}$

\section{Preparation of Basic Glycerine Soap:}

The lye solution was produced by blending sodium hydroxide $(15.7 \mathrm{gm})$ with distilled water ( $32.7 \mathrm{gm})$ in a nonmetallic pan and heating it below 50oC until it became transparent, then cooling it. The lye solution was added to the oil and fat solution, which was produced by boiling palm oil, coconut oil, and castor oil at low temperatures with intermittent stirring. Place the cover on the slow cooker and simmer for many hours (about 3 hours) until the soap mixture becomes translucent. Combine the alcohol and glycerine and pour it into the soap. Allow the soap to simmer for about 30 minutes, covered and sealed. At low to medium heat, the sugar solution is prepared, in which the sugar entirely dissolved in the water. The sugar solution was gently combined with soap after 30 minutes. Then I gently poured the soap into the soap moulds, removing the froth from the soap. The mixture was then allowed to cool to room temperature before being solidified., ${ }^{2,11}$

Table No. 1: Formulation table of Glycerine Soap

\begin{tabular}{|c|c|c|}
\hline Sr. No. & Ingredients & Quantity(gm) \\
\hline 1 & Distilled Water & 32.7 \\
\hline 2 & Sodium Hydroxide & 15.7 \\
\hline 3 & Coconut Oil & 35.3 \\
\hline
\end{tabular}




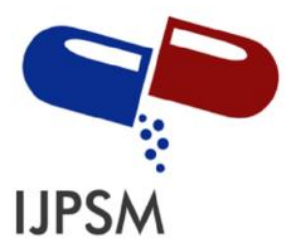

Seema U. Shinde et al, Int. Journal of Pharmaceutical Sciences and Medicine (IJPSM), Vol.6 Issue. 5, May- 2021, pg. 45-52

ISSN: 2519-9889

Impact Factor: 3.426

\begin{tabular}{|c|c|c|}
\hline 4 & Palm Oil & 34 \\
\hline 5 & Castor Oil & 34 \\
\hline 6 & Ethyl Alcohol & 38 \\
\hline 7 & Glycerine & 19.6 \\
\hline 8 & Sugar & 23.6 \\
\hline 9 & Distilled Water & 17 \\
\hline
\end{tabular}

\section{Preparation of Polyherbal Bath Soap:}

Small pieces of the prepared basic glycerine soap were broken down. Put into a pan and melted on a water bath at a temperature below $60^{\circ} \mathrm{C}$. Curcuma longa (15 gm) and Organum Vulgare (15 gm) extracts were added. After that, $100 \mathrm{ml}$ of ethanol were added. The melted soap was then mixed with $0.66 \mathrm{gm}$ stearic acid, $20 \mathrm{ml}$ cinnamon oil, and $20 \mathrm{ml}$ almond oil. For around 30 minutes, all of the components were combined together. The liquid was poured into the mold, which was then allowed to harden at room temperature, and the various differences in the features of the manufactured soap were observed. ${ }^{12}$

Table No. 2: Formulation table of Polyherbal bath Soap

\begin{tabular}{|c|c|c|}
\hline Sr. No. & Ingredients & Quantity \\
\hline 1 & Basic Glycerine Soap & $22.44 \mathrm{gm}$ \\
\hline 2 & Extract of curcuma longa & $15 \mathrm{gm}$ \\
\hline 3 & Extract of Organum Vulgare & $15 \mathrm{gm}$ \\
\hline 4 & Ethanol & $100 \mathrm{ml}$ \\
\hline 5 & Stearic acid & $0.66 \mathrm{gm}$ \\
\hline 6 & Cinnamon oil & $20 \mathrm{ml}$ \\
\hline 7 & Orange oil & $20 \mathrm{ml}$ \\
\hline
\end{tabular}




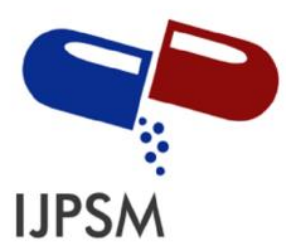

Seema U. Shinde et al, Int. Journal of Pharmaceutical Sciences and Medicine (IJPSM),

Vol.6 Issue. 5, May- 2021, pg. 45-52

ISSN: 2519-9889

Impact Factor: 3.426

\section{Evaluation of Polyherbal bath Soap Formulation:}

\section{Physical parameters:}

Against a white background, the colour, odour, and look were examined.

pH:

A digital $\mathrm{pH}$ meter was used to determine the $\mathrm{pH}$ of the produced mixtures. The formulations were diluted in $100 \mathrm{~mL}$ of distilled water and kept in the refrigerator for two hours. The $\mathrm{pH}$ of the formulation was measured using a pH meter that had previously been calibrated.

\section{Foam Height:}

A sample of 0.5 grams of soap was dispersed in $25 \mathrm{~mL}$ of distilled water. Then, it was transferred to a $100 \mathrm{ml}$ measuring cylinder, and the volume was increased to $50 \mathrm{ml}$ by adding water. 25 strokes were administered and let to stand until the aqueous volume reached $50 \mathrm{ml}$, at which point the foam height was measured above the aqueous liquid.

\section{Foam Retention:}

A $100 \mathrm{ml}$ graduated measuring cylinder was filled with $25 \mathrm{ml}$ of the $1 \%$ soap solution. Hands were placed over the cylinder and it was shaken ten times. For 4 minutes, the volume of foam was measured at 1-minute intervals. ${ }^{13}$

\section{Accelerated stability testing:}

The produced PHF was subjected to accelerated stability testing at room temperature for one week before being investigated at $50^{\circ} \mathrm{C}$ for three months. On the 0th, 15 th, 20th, 30th, 40th, 50th, 60th, 70th, 80th, and 90th days, the PHF were stored at room temperature and monitored. ${ }^{5}$

\section{Determination of percentage free alkali:}

A conical flask was filled with around 5 grams of sample and $50 \mathrm{ml}$ of neutralized alcohol. It was heated for 30 minutes on a water bath, cooled, and $1 \mathrm{~mL}$ of phenolphthalein solution was added. It was then titrated with $0.1 \mathrm{~N}$ HCL immediately. ${ }^{2}$

\section{Alcohol Insoluble Matter:}

In a conical flask, $5 \mathrm{gm}$ of material was collected. The solution was filtered through a tarred filter paper with 20 $\mathrm{ml}$ warm ethanol and dried at $105^{\circ} \mathrm{C}$ for one hour after being added to $50 \mathrm{ml}$ of warm ethanol and shaken rapidly to dissolve. The dry paper's weight was measured.

Formula:

Percentage alcohol insoluble matter $=$ Weight of the residue $\times 100 /$ Weight of sample ${ }^{14}$ 


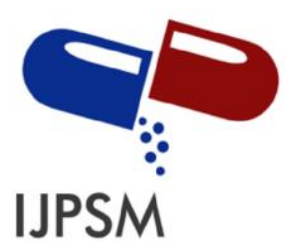

Seema U. Shinde et al, Int. Journal of Pharmaceutical Sciences and Medicine (IJPSM), Vol.6 Issue. 5, May- 2021, pg. 45-52

ISSN: 2519-9889

Impact Factor: 3.426

\section{In-Vitro Antimicrobial Activity by Agar Plate Diffusion Method:}

Antimicrobial screening was performed on the produced herbal hand sanitizer using the agar well diffusion technique. Staphylococcus aureus, E. coli, and Aspergillus niger were the organisms used. The antibacterial properties of $1 \mathrm{gm}$ of soap combined with $5 \mathrm{ml}$ of DMSO were investigated. The plates were incubated at $37^{\circ} \mathrm{C}$ for 24 hours to evaluate the inhibition zone. ${ }^{15}$.

\section{Results:}

\section{Physical parameters:}

Colour: Dark yellowish Green

Odour: Aromatic

Appearance: Good

pH:

Using a digital $\mathrm{pH}$ meter, the $\mathrm{pH}$ of the prepared formulations was determined to be 7.5 , which is the target $\mathrm{pH}$.

\section{Foam Height:}

The foam height was reported to be $25 \mathrm{~cm}$.

\section{Foam Retention:}

Foam Retention was found to be $2 \mathrm{Min}$

\section{Accelerated stability testing:}

The outcome of accelerated stability testing of a developed Polyherbal bath soap formulation was confirmed to be stable and safe to use.

\section{Determination of percentage free alkali:}

Percentage free alkali was performed successfully that was found to be 0.32

\section{Alcohol Insoluble Matter:}

Alcohol insoluble matter of prepared polyherbal bath soap was found to be $12.4 \%$

\section{In-Vitro Antimicrobial Activity by Agar Plate Diffusion Method:}

The antimicrobial activity of poly-herbal bath soap was found to be safe in this evaluation test, and the formulated poly-herbal bath soap has antimicrobial activity against bacteria such as staphylococcus aureus, E. coli, and Aspergillus Niger. The formulation had a good zone of inhibition ranging from 20 to $25 \mathrm{~mm}$, as shown in the table below: 


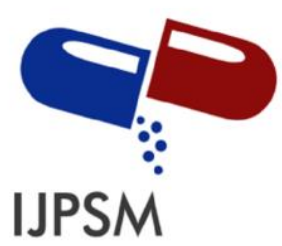

Seema U. Shinde et al, Int. Journal of Pharmaceutical Sciences and Medicine (IJPSM), Vol.6 Issue. 5, May- 2021, pg. 45-52

Table No.3: Antimicrobial Screening of prepared formulation

\begin{tabular}{|c|c|}
\hline Organism & Zone of Inhibition \\
\hline staphylococcus aureus & 20 \\
\hline E coli & 25 \\
\hline aspergillus Niger & 23 \\
\hline
\end{tabular}

\section{Conclusion:}

Curcuma longa and Organum Vulgare were chosen as ingredients for an antibacterial polyherbal bath soap. According to this study, the extracts of Curcuma longa and Organum Vulgare could be a more effective and cost-effective alternative to other antibacterial soaps. The alcoholic Soxhlet extract had the highest percentage yield and antibacterial activity. Antimicrobial test was carried on the soap. The results revealed that the soap solution had antibacterial activity, with zones of inhibition of 20, 25, and $23 \mathrm{~mm}$ on Staphylococcus aureus, Escherichia coli, and Aspergillus Niger, respectively. Furthermore, the prepared soap formulations were standardized by assessing various physicochemical properties such as $\mathrm{pH}$, colour, odour, appearance, percent Free Alkali, foam height, foam retention, and alcohol-insoluble matter, all of which were found to be satisfactory. The formulation has been determined to be safe for human's use.

\section{References}

1. Tortora g. J, grabowski s. R., 2003, principles of anatomy and physiology 10th edition published by john wiley and sons, $140-143$.

2. Pravin v. Gomase*, mo. Javed ahamad, mohd danish salahuddin, deshmukh n. I, khan g. J., 2019, development and evaluation of antibacterial polyherbal soap, international journal of pharmacy and pharmaceutical research , 15(3), 231-239.

3. Namo jeremiah akuaden, i. Y. Chindo,joel ogboji, 2019, formulation, physicochemical and antifungi evaluation of herbal soaps of azadiractaindica and ziziphusmauritiana, iosr journal of applied chemistry,12(8), 26-34.

4. Choudhari s, sutarm, chavan $\mathrm{m}, 2016$; formulation, evaluation and antibacterial efficiency of herbal hand wash, indo american journal of pharmaceutical research 6(04): 5202-2503.

5. G. Sucharita , v. Ganesh, b. Siva krishna, d. Sireesha4, s. Pavan kumar, n. Sai sasidhar, s. Revathi, dr. P. Venkatesh, 2020, formulation and evaluation of poly herbal anti-bacterial soap, , ijesc, , 27165-27173.

6. Ruckmani k, krishnamoorthy r, samuel s, kumari h. L. J, 2014, formulation of herbal bath soap from vitexnegundo leaf extract, journal of chemical and pharmaceutical sciences, (2): 95.

7. Sharma a, yadav r, guha v, soni u. N, patel j. R, 2016; formulation and evaluation of herbal hand wash, world journal of pharmacy and pharmaceutical sciences, 5(3): 675-683.

8. Londhe j, jagpat s. D, doshi c, 2015 formulations of herbal hand wash with potential antibacterial activity, international journal of research in advent technology,: 11-12.

9. Khadbadi s. S, deore s. L, bhaviskar b. D, 2011,experimental phytopharmacognosy, a comprehensive guide, 1st edition, may 8.4 .

10. N. Benchikha, m menaceur and z. 2013, Barhi, extraction and antioxidant activities of two species origanum plant containing phenolic and flavonoid compounds, journal of fundamental and applied science, 5(1), 120-128.

11. Ariza $t$, the things well make, homemade glycerin soap recipe (from scratch), august 2017, available from: https://thethingswellmake.com/homemade-glycerin-soap-recipe-from-scratch. 


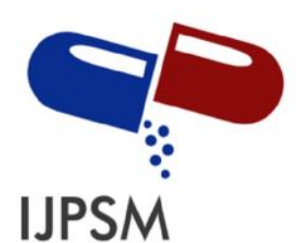

Seema U. Shinde et al, Int. Journal of Pharmaceutical Sciences and Medicine (IJPSM), Vol.6 Issue. 5, May- 2021, pg. 45-52

ISSN: 2519-9889

Impact Factor: 3.426

12. Afsar z, khanam s, 2016; formulation and evaluation of poly herbal soap and hand sanitizer, international research journal of pharmacy, 7(8): 54-57.

13. Rakesh k. Sindhu*, mansi chitkara, gagandeep kaur, arashmeet kaur, sandeep arora and i.s. sandhu, 2019, formulation development and antimicrobial evaluation of polyherbal soap, plant archives, 19( 2), 1342-1346.

14. Zeeshan afsar, salma khanam, 2019,formulation and evalution of polyherbal soap and hand sanitizer, international research journal of pharmacy, 7(8), 54-57.

15. Nikita d. Gidde *, priyanka v. Desai, priyanka v. Bagade, seema u. Shinde, manojkumar m. Nitalikar., 2021, formulation and evaluation of herbal hand sanitizer using argemone mexicana and calendula officinalis plant extract, international research journal of pharmacy, 12 (4), 34-36. 